ISAHP 1999, Kobe, Japan, August 12-14, 1999

\title{
THE MULTI-HIERARCHY INTEGRATED EVALUATING METHOD OF ENTERPRISE'S CREDIT GRADE
}

\author{
Peng Yongxing \& Yu Shangzhi \\ Department of Economics \& Information, Zhongnan University of Finance and Economics \\ \#114 Wuluo Road, Wuhan 430064, P.R.China \\ E-mail: penglong@188.net
}

\begin{abstract}
Enterprise's credit evaluation is an issue with multi-hierachy and multi-rank concerning decision-making analysis. The intention of this article is to construct a decision-making mode for enterprise's credit evaluation by establishing an index system of hierarchy structure and by using group AHP and fuzzy integrated evaluating method in order to make the evaluation job be more structural and procedural .
\end{abstract}

\section{Foreword}

Credit is the reputed conduct of paying back the loans and debts with interest by an enterprise on the promissory date in the Enterprise's financing process of capital loan and bond issue. Borrowing money and issuing bonds and stocks are all a credit relationship established between the enterprise and society. The enterprise's credit degree plays a very important role in both the formation and continuation of this credit relationship. Credit grade is an integrated evaluating conclusion drawn after a comprehensive assessment to the enterprise's running status, refunding capacity, reputation level, etc. The credit evaluation offers correct information concerning credit risks to the financial organizations \& investors, maintaining the normal operation of credit economy and ensuring the development of the capital market in a fair, just, cordial and healthy way.

China is now in an international economic environment that affected by the Asian financial crisis. Most of the enterprises' financing activities are underway with the bank as their intermediary. The State-owned professional banks are now being transformed into commercial banks. As a result of the transition from the old system to the new one and the changes of economic environment and all kinds of contradictions mingled with one another, the quality of credit capital is deteriorating and the risks of credit \& loan are on the rise and the returns of management are going downwards. In order to guarantee the safety, mobility and beneficial results of the financial capital and to avoid the financial risks, strengthening credit grade evaluation is an indispensable key link in the management of commercial banks.

The credit grade assessment in China started rather late, and compared with foreign developed capital markets, there is a great disparity in many aspects, such as the index system and integrated evaluation. It is an issue of management decision-making with multi-hierarchy and multi-rank. At present, the main method adopted within our country is the Evaluation by experts, which is simply based on the personal subjective experiences and would affect the objectivity and impartiality of the assessment to a certain extent. What's more, it's hard for this kind of method to make a reliable and rational analysis to the fuzziness and dynamic state of some indices. As the Credit Grade evaluation is of very wide range with high requirement \& large calculation, it is necessary to develop those evaluating methods that have a superior structure, a better quality for operation and that are essy to realize by using the computer. The scientific and practical method put forward in this article in which the application group AHP is combined with the fuzzy integrated evaluation and the qualitative analysis is combined with the quantitative analysis can solve this problem commendably. 


\section{Enterprise's Credit Evaluating Index System and Grade Classification}

The enterprise's grading should be made after a comprehensive study of those factors, such as enterprise's capital credit, management and development prospect. As far as the evaluation of capital credit is concerned, those factors such as the use of loan capital by the enterprise according to the policies concerned and the proportion of self-owned capital and debt repayment should be checked in advance. In the case of management, those factors such as the production and sales, profits and financing management of the enterprise should be examined beforehand. As for the evaluation of development prospect, it is necessary to make a prior investigation on those factors such as the sales of products, the supply of raw materials, the advancing level of equipment and technology and the level of competence of administrative personnel of the enterprise. For this reason ,the establishment of a credit evaluation index system is essential.

At present, the evaluating standards and index systems enacted by various civil banks are different. According to the principle of being systemic, scientific, comparable \& easily operational, this article constructs an evaluation index system with a multi-level hierarchy structure after consulting comprehensively the relevant banks' credit evaluation materials.

The Index System is divided into three hierarchies: The first hierarchy is the General Index, i. e. the Credit Level $(A)$; the second hierarchy is Structure Index, which sets up 4 indices of Security $\left(B_{1}\right)$, Mobility $\left(B_{2}\right)$, Efficiency $\left(B_{3}\right)$, Development Prospect $\left(B_{4}\right)$; the third hierarchy is Analysis Index, which has 12 indices that belongs respectively to different structure indices of above-mentioned second hierarchy. Security index $\left(B_{1}\right)$ includes Capital Debt Rate $\left(C_{1}\right)$, Overdue Loan Ratio $\left(C_{2}\right)$, Self-owned floating Capital Rate $\left(C_{3}\right)$; Mobility index $\left(B_{2}\right)$ contains: 3-item Capital Occupying-rate in Floating Capital $\left(C_{4}\right)$, Velocity of Floating Capital $\left(\mathrm{C}_{5}\right)$, Loan Repaying Rate $\left(\mathrm{C}_{6}\right)$; Efficiency Index $\left(\mathrm{B}_{3}\right)$ contains: Production-sales rate $\left(\mathrm{C}_{7}\right)$, Capital Profit Margin $\left(\mathrm{C}_{8}\right)$; Development prospect Index $\left(\mathrm{B}_{4}\right)$ has four indices: Market Prospect for Products $\left(C_{9}\right)$, Raw-material Assuring Level $\left(C_{t 0}\right)$, Advancing Level of Equipment and Technology $\left(C_{11}\right)$, Level of competence of Administrative Personnel $\left(C_{12}\right), C_{1} \sim C_{8}$ are quantitative analysis indices, while $C_{9}$ $\sim \mathrm{C}_{12}$ are qualitative analysis indices.

In the light of international practice, the Credit Grade is usually classified into 3 grades, 9 levels, $i$. e. the first grade (AAA, AA, A), the second grade (BBB, BB, B), the third grade (CCC, $\mathrm{CC}, \mathrm{C}$ ). Based on the practical operations in civil commercial banks, this article simplifies the credit degree into 5 levels. They are:

\begin{tabular}{|c|c|c|c|c|c|}
\hline Wrare, & 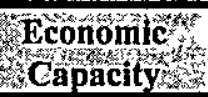 & Management & 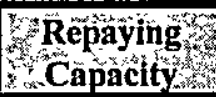 & Weputation & 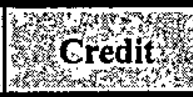 \\
\hline $\mathrm{AlA}^{2}$ & Best & Best & Strongest & Best & Highest \\
\hline S AA & Better & Better & Stronger & Better & Higher \\
\hline 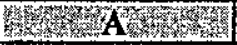 & Good & Good & Strong & Good & Good \\
\hline PB & Normal & Normal & Limited & Normal & Normal \\
\hline BB \& \& B low & $\mathrm{Bad}$ & $\mathrm{Bad}$ & $\mathrm{Bad}$ & $\mathrm{Bad}$ & Risk \\
\hline
\end{tabular}

According to the condition of enterprises' credit grades, banks formulate relevant policies on loan arrangement, contract guarantee, earnest money system and bonds issuing etc., so as to achieve the goal of supporting the better and restraining the worse and preventing the risks.

\section{Mode of Multi-hierarchy Integrated Evaluating Method of Credit Grade}

Credit grade evaluation relates to many factors, social, economic and technological. It is necessary to make an integrated assessment with multi-hierarchy to the credit indices such as security, mobility, efficiency, development prospect. Some indices are fuzzy \& mobile, which brings many difficulties to the evaluation. The integrated evaluating mode with multi-hierarchy researched \& established by this article can solve above-mentioned difficulties well. The constructing steps of enterprise's credit grade integrated evaluating mode with multi-hierarchy are as follows: 
(1) Adopting Group AHP method to establish the weight of indices with hierarchy:

In the index system of structure with hierarchy adopting Group AHP method to calculate the weight of indices with hierarchy setting classifying indices: $B_{k}(k=1,2,3, \ldots, m)$, the analytic indices attached are $C_{t}$ $\left(l=1,2,3, \ldots, n_{k}\right)$, weight of experts in evaluating committee is $\lambda_{l}(l=1,2,3, \ldots, s)$, and $\sum_{t=1}^{s} \lambda_{t}=1$.Under principle $B_{k}$, experts $t$ are marked on the proportion of $1 \sim 9$. Adopting AHP practical program to construct the judgement matrix $A_{k}^{(t)}$, to calculate the maximum character value and the relative character vector:

$$
W_{k}^{(1)}=\left(w_{1}^{(i)}, w_{2}^{(i)}, \cdots, w_{n_{k}}^{(1)}\right)^{r}
$$

and doing the coherency examination. Using weighting average integrated vector method to calculate the group weight vector with hierarchy:

$$
W_{k}=\left(w_{1}, w_{2}, \cdots, w_{n_{k}}\right)^{T} \text { and } W_{j}=\sum_{t=1}^{s} \lambda_{t} w_{j}^{(i)}, j=1,2, \cdots, n_{k}
$$

At the same time, calculating the weight vector of classifying index $\mathrm{B}_{\mathrm{k}}$ under principle $A$.

$$
W=\left(w_{1}, w_{2}, w_{3}, \ldots, w_{m}\right)^{\mathrm{T}}
$$

(2) Using fuzzy statistics means to determine the indices' fuzzy vector:

Setting index set $U=\left\{B_{l}, B_{2}, B_{3}, B_{m}\right\}$, thereinto the subset $B_{l} \cap B_{j}=\Phi, i \neq j, B_{k}=\left\{u_{k 1}, u_{k 2}, u_{k 3}, \cdots, u_{k n_{k}}\right\}$, commenting set $V=\{A A A, A A, A, B B B, B B\}=\left\{v_{1}, v_{2}, v_{3}, v_{4}, v_{s}\right\}$.

For the qualitative index $u_{i j}$, use fuzzy statistics method to determine it. For the subordinate degree $\mu_{i j}^{(t)}$ of grade $v_{t}$, thereby to get fuzzy vector:

$$
R_{i j}=\left(\mu_{i j}^{(2)}, \mu_{i j}^{(2)}, \mu_{i j}^{(3)}, \mu_{i j}^{(4)}, \mu_{i j}^{(3)}\right)^{\gamma} .
$$

For the quantitative index $u_{i j}$, use constructive broken-line-type subordinate function to set the subordinate degree. Let's set $u_{i j}$ as the benefit index, its subordinate function is:

$$
\begin{aligned}
& \mu_{i j}^{(1)}= \begin{cases}1, & u \geq b \\
\left(u-x_{3}\right) / d, & x_{3} \leq u<b\end{cases} \\
& \mu_{i}^{(i)}=\left\{\begin{array}{ll}
\left(x_{5-t+1}-u\right) / d, & x_{5-1} \leq u<x_{5-t+1} \\
\left(u-x_{3-t-1}\right) / d, & x_{5-t-1} \leq u<x_{5-1}
\end{array} \quad(t=2,3,4)\right. \\
& \mu_{i j}^{(3)}= \begin{cases}\left(x_{1}-u\right) / d, & a \leq u<x_{1} \\
1, & u<a\end{cases}
\end{aligned}
$$

$a \& b$ respectively denotes the worst \& the best value of index $u_{i j}, x_{1}, x_{2} \& x_{3}$ are the equidistance points that inserted between interval $(a, b) ; d=(b-a) / 3$. The cost-type index can also be dealt in the same way.

(3) Using fuzzy integrated evaluating method to set credit grade:

Setting the matrix of index subset $\mathrm{B}_{\mathrm{k}}$ on commenting set as:

The integrated evaluating vector of $B_{k}$ is:

$$
R_{k}=\left(r_{k 1}, r_{k 2}, \cdots, r_{k n_{k}}\right)^{r}
$$

$$
B_{k}=W_{k}^{T} R_{k}=\left(b_{k 1}, b_{k 2}, b_{k 3}, b_{k s}, b_{k s}\right)
$$

The integrated evaluating vector of credit grade is: 


$$
A=W^{\tau}\left(\begin{array}{c}
B_{1} \\
B_{2} \\
\vdots \\
B_{m}
\end{array}\right)=\left(a_{1}, a_{2}, a_{3}, a_{4}, a_{3}\right)
$$

\section{Epilogue}

The comprehensive credit-grade evaluating mode with hierarchy put forward in this article was used to assess the credit grade of one major state-owned enterprise in Wuhan, and the result was very satisfactory. This method has the characteristics of being scientific, practical and easy for operation. The joint analysis of Structure Index and Analytic Index is beneficial to the cooperation between banks and enterprises and offers scientific decision-making foundation for the enterprises to improve their operation \& management.

\section{Mainly Reference Literatures}

Wang Lianfen (1990) Introduction to Hierarchy Analysis Method Publishing Office of People's University of China, 245-248.

Peng Yongxing (1994) Theory and Method of System Evaluation China Economic Publishing Office, 310316. 